\title{
LncRNA2Function: a comprehensive resource for functional investigation of human IncRNAs based on RNA-seq data
}

Qinghua Jiang ${ }^{1 \dagger}$, Rui $\mathrm{Ma}^{2 \dagger}$, Jixuan $\mathrm{Wang}^{3}$, Xiaoliang $\mathrm{Wu}^{3}$, Shuilin $\mathrm{Jin}^{4}$, Jiajie Peng ${ }^{2}$, Renjie $\mathrm{Tan}^{2}$, Tianjiao Zhang ${ }^{2}$, Yu Li ${ }^{1}$, Yadong Wang ${ }^{2^{*}}$

From 10th International Symposium on Bioinformatics Research and Applications (ISBRA-14)

Zhangjiajie, China. 28-30 June 2014

\begin{abstract}
Background: The GENCODE project has collected over 10,000 human long non-coding RNA (InCRNA) genes. However, the vast majority of them remain to be functionally characterized. Computational investigation of potential functions of human IncRNA genes is helpful to guide further experimental studies on IncRNAs.

Results: In this study, based on expression correlation between IncRNAs and protein-coding genes across 19 human normal tissues, we used the hypergeometric test to functionally annotate a single IncRNA or a set of IncRNAs with significantly enriched functional terms among the protein-coding genes that are significantly coexpressed with the IncRNA(s). The functional terms include all nodes in the Gene Ontology (GO) and 4,380 human biological pathways collected from 12 pathway databases. We successfully mapped 9,625 human IncRNA genes to GO terms and biological pathways, and then developed the first ontology-driven user-friendly web interface named IncRNA2Function, which enables researchers to browse the IncRNAs associated with a specific functional term, the functional terms associated with a specific IncRNA, or to assign functional terms to a set of human IncRNA genes, such as a cluster of co-expressed IncRNAs. The IncRNA2Function is freely available at http://mlg.hit. edu.cn/Incrna2function.
\end{abstract}

Conclusions: The LncRNA2Function is an important resource for further investigating the functions of a single human IncRNA, or functionally annotating a set of human IncRNAs of interest.

\section{Background}

Thousands of human long non-coding RNAs (lncRNAs) have been identified and emerging studies have revealed that IncRNAs play important roles in a wide range of biological processes $[1,2]$ and diseases [3,4]. However, functions of most human lncRNAs are still elusive. Functions of a lncRNA may be determined by loss- and gain-offunction biological experiments $[5,6]$. However, this is not straightforward since it is difficult to knock down a lncRNA expressed as multiple isoforms. Alternatively,

\footnotetext{
* Correspondence: ydwang@hit.edu.cn

+ Contributed equally

${ }^{2}$ School of Computer Science and Technology, Harbin Institute of

Technology, Harbin, Heilongjiang 150001, China

Full list of author information is available at the end of the article
}

computational exploration of human lncRNA functions is helpful to guide further studies on lncRNAs.

Currently, computational investigation of IncRNA functions is still at its early development stage, since it is a considerable challenge due to the characteristics of lncRNAs, e.g., many lncRNA gene sequences are not conserved and do not contain conserved sequence motifs [7], which makes it difficult to infer potential functions of lncRNAs based on their sequences alone. In addition, few available molecular interaction data of new identified lncRNAs also hamper the lncRNA functional annotations $[8,9]$.

Since genes with similar expression patterns across multiple conditions may share similar functions [10] or be involved in related biological pathways [11], identifying protein-coding genes that are co-expressed with 
lncRNAs may help to assign functions to the lncRNAs. By analyzing lncRNA-mRNA co-expression pattern, Guttman et al. identified several sets of mouse lncRNAs associated with protein-coding gene sets of distinct GO functional categories [12]. In addition, two recent studies separately constructed a mouse co-expressed lncRNA-mRNA network using mouse microarray data and assigned functions to 340 and 1,625 mouse lncRNAs [13,14].

Despite accumulating insights into the mouse lncRNA functions, more than 10,000 human lncRNAs remain to be functionally characterized. Firstly, given a single human lncRNA gene, it needs to be established whether it executes crucial biological functions. Secondly, given a set of human lncRNA genes such as differential lncRNAs between cancer and normal samples, it is an important downstream task to identify significantly enriched function terms. Thirdly, given an important functional term such as a Wnt signalling pathway, how to know which lncRNAs may be involved in the pathway.

Here, based on the expression correlation between lncRNAs and protein-coding genes inferred from RNAseq data of 19 human normal tissues, we functionally annotated 9,625 human lncRNAs with significantly enriched functional terms among the co-expressed protein-coding genes, and developed a user-friendly web interface for the lncRNA community to obtain the lncRNAs associated with a specific functional term, the functional terms associated with a specific lncRNA, or to assign functions to a set of human lncRNAs of interest.

\section{Methods}

\section{Data sources}

We downloaded: (1) genomic coordinates of all human lncRNA genes and protein-coding genes from the GENCODE V15 [15], (2) paired-end RNA-Seq data of 19 human normal tissues from the Human Body Map 2 project (ArrayExpress accession no. E-MTAB-513) and another study (GEO accession no. GSE30554), (3) GO assignments for the proteins of the human UniProtKB Complete Proteome from the website of the Gene Ontology Project [16], (4) 4,380 human biological pathways from the ConsensusPathDB database which integrated 12 pathway databases [17].

\section{Workflow of LncRNA2Function}

The schematic workflow of lncRNA2Function is shown in Figure 1. Firstly, RNA-Seq reads sequenced in 19 human normal tissues were firstly mapped to human genome (hg19) using tophat with the default parameters [18], and expression values of all human lncRNA and protein-coding genes in the 19 tissues were computed using cufflinks with the default parameter [19]. Secondly, the Pearson Correlation Coefficients (PCC) of all
lncRNA-mRNA gene pairs were computed, and a set of significantly co-expressed protein-coding genes was thus obtained for each human lncRNA (significant: the absolute value of the Pearson correlation coefficient $>0.9$ and adjusted $P$-value $<0.05)$. Thirdly, each lncRNA was functionally annotated with significantly enriched GO terms and biological pathways among the set of co-expressed protein-coding genes. Finally, a web interface was developed to facilitate researchers to browse or search the functions associated with a given lncRNA or lncRNAs associated with a specific function, or to functionally annotate a set of lncRNA genes of interest.

\section{GO and pathway enrichment analysis of human IncRNAs}

Given a single human lncRNA gene, we obtained a set of protein-coding genes that were significantly co-expressed with the lncRNA. The lncRNA was then functionally annotated with significantly enriched GO and pathway terms among the set of co-expressed protein-coding genes. The enrichment analysis was separately executed for each term (denoted as T), and a P-value of each term was calculated by the hypergeometric test:

$$
p=\frac{\sum_{i=m}^{\min (n, M)}\left(\begin{array}{l}
M \\
i
\end{array}\right)\left(\begin{array}{c}
N-M \\
n-i
\end{array}\right)}{\left(\begin{array}{l}
N \\
n
\end{array}\right)}
$$

Herein, $N$ is the number of all protein-coding genes in human genome, $M$ is the number of protein-coding genes that were annotated in the functional term T, $n$ is the number of protein-coding genes that were significantly co-expressed with the lncRNA, and $m$ is the number of protein-coding genes that were both significantly co-expressed with the lncRNA and annotated in the functional term $\mathrm{T}$.

For each GO term, protein-coding genes directly belong to it as well as those belong to any of its offspring terms are all considered as its annotated genes. Since the statistical analysis is not appropriate to problems with small sample size, those GO and pathway terms with less than 5 annotated protein-coding genes and those lncRNAs with less than 5 co-expressed protein-coding genes were excluded form the enrichment analysis.

Given a set of human lncRNA genes of interest, LncRNA2Function first identify a set of protein-coding genes, each of which are significantly co-expressed with one or more of the given lncRNAs across 19 human normal tissues. Then, the set of lncRNAs are functionally annotated with the enriched GO and pathway terms among the set of co-expressed protein-coding genes. If researchers input a large number of lncRNAs, the LncRNA2Function may obtain thousands of co-expressed 


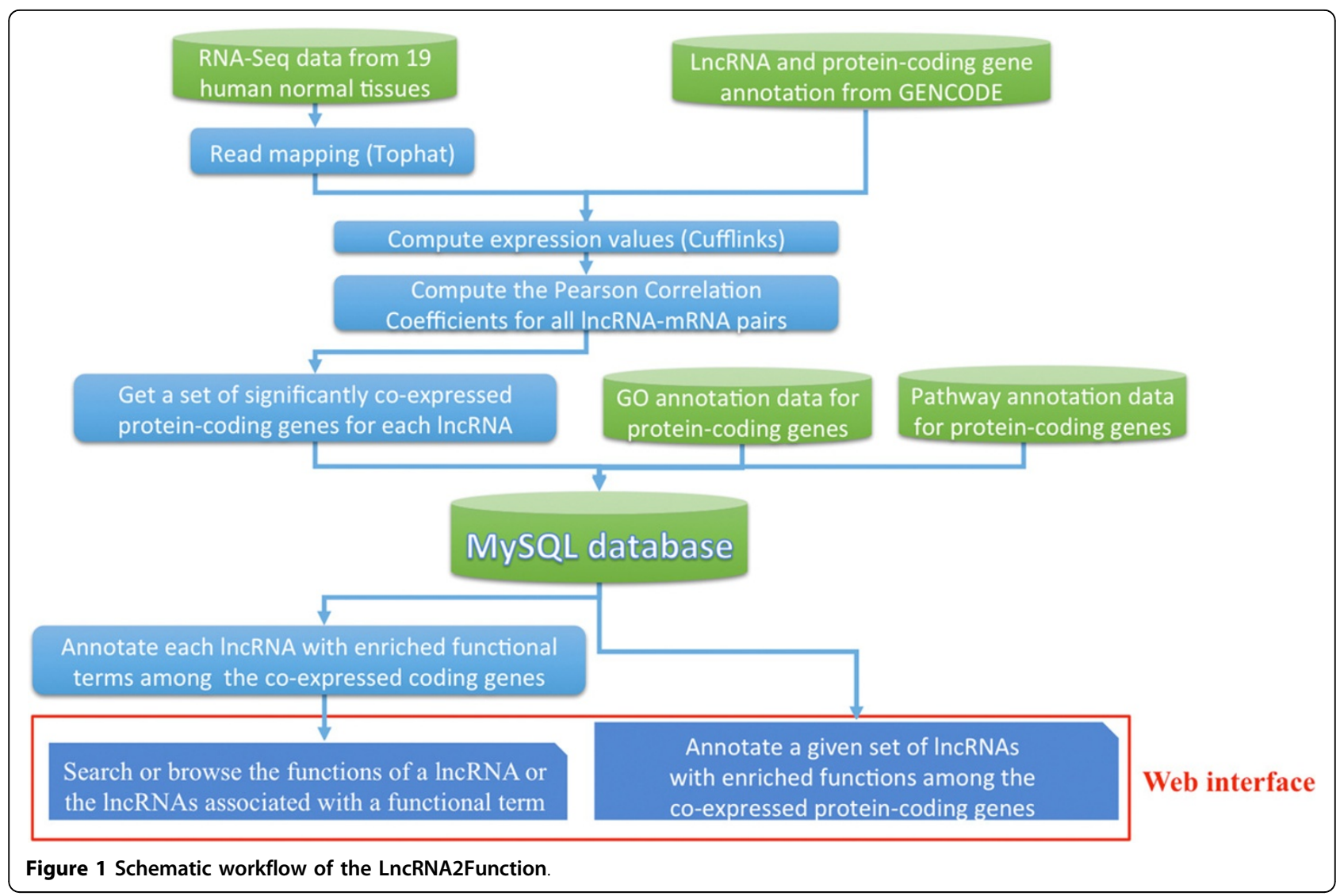

protein-coding genes, some of which are co-expressed with only one of the lncRNAs. To improve the accuracy of functional assignments to the set of lncRNAs, users can select the protein-coding genes that are co-expressed with at least $K \operatorname{lncRNAs}$ (the $K$ can be assigned based on the size of the set of lncRNAs. The default $K$ is 1 ).

There are two commonly used methods for controlling false discovery rate (FDR), the Benjamini-Yekutieli (BY) method [20] and the Benjamini-Hochberg (BH) method [21]. The former is suitable for positively related multiple hypothesis tests whereas the later is suitable for independent multiple hypothesis tests [22]. Since the hierarchical GO terms are often dependent, we chose the BY method to correct the P-values from the GO enrichment analysis, and the $\mathrm{BH}$ method to correct the $P$-values from the pathway enrichment analysis. The significant cut-off of corrected P-value was set as 0.05 .

\section{Results and discussion}

\section{Functional annotations of a single human IncRNA}

We obtained 5,232,299 significantly co-expressed pairs between 9,625 human lncRNA genes and 10,919 proteincoding genes. Each of the 9,625 lncRNAs was functionally annotated with significantly enriched GO terms and biological pathways among its co-expressed protein-coding genes. Consequently, we obtained 614,174 associations between 5,735 lncRNA genes and 3,890 GO terms, and 240,050 associations between 6,062 lncRNAs and 3,034 biological pathways. To understand the major functions of lncRNAs, we ranked GO biological processes and biological pathways according to the number of lncRNAs associated with each of them. Among the top ranked $200 \mathrm{GO}$ biological processes and pathways, we found that lncRNAs play roles in many important biological processes, including defense response to bacterium, DNA packaging, meiosis, developmental process, metabolic process, cell cycle process, cell adhesion, cell differentiation, Jak-STAT signaling pathway and PI3K-Akt signaling pathway. A part of the enriched functions of IncRNAs have been validated by published studies [23-26].

\section{Case studies}

Due to the lack of a large gold standard dataset of known human lncRNA functions, five well-studied lncRNAs were used as the examples to show the usefulness of LncRNA2Function.

\section{Case study 1: HOTAIR}

The HOTAIR is a well-studied lncRNA. Rinn et al. found that the HOTAIR interacts with the Polycomb 
repressive complex 2 (PRC2) to modify chromatin and repress transcription of the HOX genes, which regulate development [27]. Niinuma et al. revealed that overexpression of HOTAIR was strongly associated with highrisk grade and metastasis among gastrointestinal stromal tumors (GIST) specimens, and knockdown of HOTAIR suppressed GIST cell invasiveness [28]. In addition, Gupta et al. demonstrated that the lncRNA HOTAIR is increased in expression in primary breast tumors and metastases, and enforced expression of HOTAIR in epithelial cancer cells leaded to altered histone H3 lysine 27 methylation, gene expression, and increased cancer invasiveness and metastasis in a manner dependent on PRC2. Conversely, loss of HOTAIR can inhibit breast cancer invasiveness [26].

To examine whether our LncRNA2Function can functionally annotate the lncRNA HOTAIR with development and metastasis-related functional terms, we applied the LncRNA2Function to the HOTAIR, and found that it was annotated with $99 \mathrm{GO}$ biological processes and 33 pathways (The significant Corrected P-value cutoff is 0.05). Of the $99 \mathrm{GO}$ biological processes, $77.8 \%$ (77/99) are involved in the development and morphogenesis as expected (The top $20 \mathrm{GO}$ development-related biological processes are shown in Table 1), and 9.1\% (9/99) are involved in the cell invasion and metastasis, such as cell migration (GO:0016477), cell adhesion (GO:0007155), biological adhesion (GO:0022610) and cell motility (GO:0048870). In addition, Of the 33 biological pathways,
$72.7 \%(24 / 33)$ are involved in the cell invasion and metastasis (Table 2), such as focal adhesion, beta1 integrin cell surface interactions, NCAM1 interactions, Syndecan-1mediated signaling events, PI3K-Akt signaling pathway and cell surface interactions at the vascular wall. Taken together, these results demonstrated that our LncRNA2Function can successfully recall the known functions of a well-studied lncRNA HOTAIR and suggested that it is applicable to infer potential functions of new identified lncRNAs.

\section{Case study 2: HCP5}

The IncRNA HCP5 was found to be associated with AIDS [29-31]. Rodriguez-Novoa et al. analyzed a total of 245 HIV patients and found a good correlation between HLAB 5701 and HCP5 (negative and positive predictive values of $100 \%$ and $93 \%$, respectively). Colombo et al. analyzed that 1,103 singles infected with human immunodeficiency virus (HIV) and concluded that HCP5 genotyping could serve as a simple screening tool for ABC-HSR, particularly in settings where sequence-based HLA typing is not available.

To assess whether the HCP5 can be correctly predicted to have immune-related functions, we applied our LncRNA2Function to it and found that HCP5 was annotated with 549 GO biological processes terms and 270 biological pathways. As expected, most of them are indeed immune system and response functional terms, which are strongly associated with the development of

Table 1 The top 20 biological processes assigned to the development-regulating HOTAIR by LncRNA2Function

\begin{tabular}{|c|c|c|c|c|}
\hline GO term & Background frequency & Sample frequency & P-value & $\begin{array}{l}\text { Corrected } \\
\text { P-value }\end{array}$ \\
\hline System development & $3253 / 20447$ & $38 / 74$ & $1.63 \mathrm{E}-12$ & 2.37E-08 \\
\hline Anatomical structure morphogenesis & $1884 / 20447$ & $28 / 74$ & 2.45E-11 & 7.10E-08 \\
\hline Tissue development & $1183 / 20447$ & $23 / 74$ & 1.33E-11 & 7.10E-08 \\
\hline Embryonic skeletal system development & $120 / 20447$ & $10 / 74$ & $1.73 \mathrm{E}-11$ & 7.10E-08 \\
\hline Anatomical structure development & $3717 / 20447$ & $39 / 74$ & 2.07E-11 & 7.10E-08 \\
\hline Skeletal system development & $388 / 20447$ & $14 / 74$ & $1.01 \mathrm{E}-10$ & 2.44E-07 \\
\hline Organ morphogenesis & $790 / 20447$ & $18 / 74$ & 2.89E-10 & 4.73E-07 \\
\hline Multicellular organismal development & $3830 / 20447$ & $38 / 74$ & $2.56 \mathrm{E}-10$ & 4.73E-07 \\
\hline Developmental process & $4248 / 20447$ & $40 / 74$ & $2.93 \mathrm{E}-10$ & 4.73E-07 \\
\hline Organ development & $2271 / 20447$ & $29 / 74$ & $3.63 \mathrm{E}-10$ & 5.27E-07 \\
\hline Skeletal system morphogenesis & 189/20447 & $10 / 74$ & 1.54E-09 & $1.72 \mathrm{E}-06$ \\
\hline Multicellular organismal process & $5336 / 20447$ & $44 / 74$ & 1.39E-09 & $1.72 \mathrm{E}-06$ \\
\hline Single-multicellular organism process & $5125 / 20447$ & $43 / 74$ & $1.51 \mathrm{E}-09$ & $1.72 \mathrm{E}-06$ \\
\hline Extracellular matrix organization & $204 / 20447$ & $10 / 74$ & 3.23E-09 & $3.28 \mathrm{E}-06$ \\
\hline Extracellular structure organization & 205/20447 & $10 / 74$ & 3.39E-09 & $3.28 \mathrm{E}-06$ \\
\hline Head development & $52 / 20447$ & $6 / 74$ & $3.26 \mathrm{E}-08$ & $2.96 \mathrm{E}-05$ \\
\hline Embryonic skeletal system morphogenesis & $91 / 20447$ & $7 / 74$ & 3.86E-08 & 3.30E-05 \\
\hline Single-organism developmental process & $3161 / 20447$ & $31 / 74$ & 4.39E-08 & 3.54E-05 \\
\hline Chordate embryonic development & $557 / 20447$ & $13 / 74$ & 9.05E-08 & $6.57 \mathrm{E}-05$ \\
\hline Embryo development ending in birth or egg hatching & $564 / 20447$ & $13 / 74$ & 1.05E-07 & 7.23E-05 \\
\hline
\end{tabular}


Table 2 The metastasis-associated HOTAIR was annotated with metastasis-related GO and pathway terms by LncRNA2Function

\begin{tabular}{|c|c|c|c|c|c|}
\hline Database & Functional term & Background frequency & Sample frequency & P-value & Corrected P-value \\
\hline $\mathrm{GO}$ & Locomotion & $1022 / 20447$ & $14 / 74$ & $1.53 \mathrm{E}-05$ & 0.003417 \\
\hline $\mathrm{GO}$ & Cell migration & $603 / 20447$ & $10 / 74$ & 6.07E-05 & 0.010887 \\
\hline $\mathrm{GO}$ & Cell adhesion & $790 / 20447$ & $11 / 74$ & $1.21 \mathrm{E}-04$ & 0.020655 \\
\hline $\mathrm{GO}$ & Biological adhesion & $792 / 20447$ & $11 / 74$ & $1.24 \mathrm{E}-04$ & 0.020663 \\
\hline $\mathrm{GO}$ & Cell motility & $664 / 20447$ & $10 / 74$ & $1.34 \mathrm{E}-04$ & 0.021695 \\
\hline $\mathrm{GO}$ & Positive regulation of cell-cell adhesion & $33 / 20447$ & $3 / 74$ & 2.30E-04 & 0.032376 \\
\hline PID & Beta1 integrin cell surface interactions & $75 / 20447$ & $7 / 74$ & $9.92 \mathrm{E}-09$ & $2.22 \mathrm{E}-06$ \\
\hline Reactome & Extracellular matrix organization & $102 / 20447$ & $7 / 74$ & 8.54E-08 & 9.57E-06 \\
\hline KEGG & ECM-receptor interaction & $110 / 20447$ & $7 / 74$ & 1.44E-07 & 1.07E-05 \\
\hline $\mathrm{INOH}$ & Integrin & $141 / 20447$ & $7 / 74$ & $7.82 \mathrm{E}-07$ & 4.01E-05 \\
\hline Wikipathways & Focal Adhesion & $203 / 20447$ & $7 / 74$ & 8.79E-06 & $2.46 \mathrm{E}-04$ \\
\hline KEGG & Focal adhesion & $219 / 20447$ & $7 / 74$ & $1.44 \mathrm{E}-05$ & $3.58 \mathrm{E}-04$ \\
\hline PID & Beta3 integrin cell surface interactions & $47 / 20447$ & $4 / 74$ & $2.51 \mathrm{E}-05$ & $5.61 \mathrm{E}-04$ \\
\hline PID & Syndecan-1-mediated signaling events & $50 / 20447$ & $4 / 74$ & $3.21 \mathrm{E}-05$ & $6.53 \mathrm{E}-04$ \\
\hline PID & Integrin cell surface interactions & $58 / 20447$ & $4 / 74$ & $5.78 \mathrm{E}-05$ & 0.001079 \\
\hline PID & Integrins in angiogenesis & $73 / 20447$ & $4 / 74$ & $1.42 \mathrm{E}-04$ & 0.002454 \\
\hline Reactome & Integrin cell surface interactions & $88 / 20447$ & $4 / 74$ & $2.93 \mathrm{E}-04$ & 0.004373 \\
\hline KEGG & PI3K-Akt signaling pathway & $361 / 20447$ & $7 / 74$ & $3.29 \mathrm{E}-04$ & 0.004606 \\
\hline Reactome & Cell surface interactions at the vascular wall & $104 / 20447$ & $4 / 74$ & $5.53 \mathrm{E}-04$ & 0.006566 \\
\hline Reactome & Signaling by PDGF & $187 / 20447$ & $5 / 74$ & $5.86 \mathrm{E}-04$ & 0.006566 \\
\hline Reactome & NCAM1 interactions & $45 / 20447$ & $3 / 74$ & $5.79 E-04$ & 0.006566 \\
\hline Reactome & NCAM signaling for neurite out-growth & $72 / 20447$ & $3 / 74$ & 0.002268 & 0.023101 \\
\hline Reactome & Platelet Adhesion to exposed collagen & $22 / 20447$ & $2 / 74$ & 0.002848 & 0.025533 \\
\hline PID & VEGFR3 signaling in lymphatic endothelium & $25 / 20447$ & $2 / 74$ & 0.003673 & 0.031645 \\
\hline Reactome & Basigin interactions & $26 / 20447$ & $2 / 74$ & 0.003969 & 0.032935 \\
\hline KEGG & TGF-beta signaling pathway & $92 / 20447$ & $3 / 74$ & 0.004537 & 0.036298 \\
\hline PID & Wnt signaling network & 29/20447 & $2 / 74$ & 0.004924 & 0.038039 \\
\hline Reactome & Degradation of the extracellular matrix & $32 / 20447$ & $2 / 74$ & 0.005974 & 0.043169 \\
\hline Reactome & Activation of Matrix Metalloproteinases & $32 / 20447$ & $2 / 74$ & 0.005974 & 0.043169 \\
\hline PID & Alpha4 beta1 integrin signaling events & $34 / 20447$ & $2 / 74$ & 0.006725 & 0.046835 \\
\hline
\end{tabular}

AIDS. The top $20 \mathrm{GO}$ biological terms assigned to the HCP5 are shown in Table 3 while the top 20 biological pathways assigned to the HCP5 are shown in Table 4.

\section{Case study 3: HULC}

The lncRNA HULC is highly upregulated in liver cancer and plays an important role in tumorigenesis [32]. Depletion of HULC resulted in a significant deregulation of several genes involved in liver cancer [33], and colorectal carcinomas that metastasize to the livers but not to lymph nodes experience an up-regulation of HULC in all the samples tested $(n=8)$, with a strong-to-moderate expression in six out of eight [34].

To examine whether the HULC was predicted to have liver-related functions, we analyzed it using our lncRNA2Function. Expectedly, LncRNA2Function also works well to functionally annotate the HULC. The results showed that it was annotated with $373 \mathrm{GO}$ biological processes and 383 biological pathways (the significant P-value cutoff is 0.05$)$. Of the $373 \mathrm{GO}$ biological processes and 383 pathways, over $80 \%$ are involved in the known liver-related biological functions, such as metabolic function, bile secretion, lipid transport and homeostasis, cholesterol homeostasis, regulation of blood coagulation, protein-lipid complex subunit organization, detoxification, Immune defense and complement activation. The Figure 2 shows the top 25 GO functional terms assigned to the HULC, and the Table 5 shows the top 20 pathways enriched in protein-coding genes that are co-expressed with the liverrelated lncRNA HULC.

\section{Case study 4: $\mathrm{H} 19$}

H19 is an important lncRNA that play roles in the infertility [35] and multiple cancers such as breast cancer [36,37], cervical cancer [38], liver cancer [39,40] and bladder cancer [41]. For example, Korucuoglu et al. revealed that $\mathrm{H} 19$ expression was lower in the infertility group as compared to the control group (4-fold change, 
Table 3 The top 20 biological processes assigned to the AIDS-related IncRNA HCP5 by LncRNA2Function.

\begin{tabular}{|c|c|c|c|c|}
\hline GO term & Background frequency & Sample frequency & P-value & $\begin{array}{l}\text { Corrected } \\
\text { P-value }\end{array}$ \\
\hline Immune system process & $1581 / 20447$ & $208 / 458$ & $1.0 \mathrm{E}-109$ & $3.49 \mathrm{E}-105$ \\
\hline Immune response & $867 / 20447$ & $148 / 458$ & $1.57 E-90$ & $2.70 \mathrm{E}-86$ \\
\hline Defense response & $968 / 20447$ & $144 / 458$ & 2.37E-79 & $2.72 \mathrm{E}-75$ \\
\hline Regulation of immune system process & $879 / 20447$ & $131 / 458$ & $1.16 \mathrm{E}-71$ & 9.95E-68 \\
\hline Regulation of immune response & $527 / 20447$ & $105 / 458$ & $9.62 \mathrm{E}-70$ & $6.62 \mathrm{E}-66$ \\
\hline Response to stimulus & $6195 / 20447$ & $312 / 458$ & $9.35 \mathrm{E}-64$ & $5.36 \mathrm{E}-60$ \\
\hline Cell activation & $557 / 20447$ & $89 / 458$ & $3.11 \mathrm{E}-50$ & $1.53 \mathrm{E}-46$ \\
\hline Leukocyte activation & $344 / 20447$ & $73 / 458$ & $5.00 \mathrm{E}-50$ & $2.15 \mathrm{E}-46$ \\
\hline Regulation of response to stimulus & $2379 / 20447$ & $173 / 458$ & $1.23 \mathrm{E}-48$ & $4.72 \mathrm{E}-45$ \\
\hline Positive regulation of immune system process & $522 / 20447$ & $84 / 458$ & $1.39 \mathrm{E}-47$ & 4.77E-44 \\
\hline Response to stress & $2747 / 20447$ & $181 / 458$ & $4.76 \mathrm{E}-45$ & $1.26 \mathrm{E}-41$ \\
\hline Signal transduction & $3612 / 20447$ & $205 / 458$ & 4.25E-42 & $1.04 \mathrm{E}-38$ \\
\hline Positive regulation of immune response & $331 / 20447$ & $63 / 458$ & 4.17E-40 & $9.56 \mathrm{E}-37$ \\
\hline Cellular response to stimulus & $4596 / 20447$ & $231 / 458$ & $5.11 \mathrm{E}-40$ & $1.10 \mathrm{E}-36$ \\
\hline Lymphocyte activation & $276 / 20447$ & $58 / 458$ & $1.81 \mathrm{E}-39$ & $3.66 \mathrm{E}-36$ \\
\hline Innate immune response & $474 / 20447$ & $72 / 458$ & $6.13 \mathrm{E}-39$ & 1.17E-35 \\
\hline Positive regulation of response to stimulus & $1154 / 20447$ & $106 / 458$ & $6.43 \mathrm{E}-37$ & $1.16 \mathrm{E}-33$ \\
\hline T cell activation & $176 / 20447$ & $46 / 458$ & $5.40 \mathrm{E}-36$ & $9.28 \mathrm{E}-33$ \\
\hline Single organism signaling & $4081 / 20447$ & $208 / 458$ & $1.23 \mathrm{E}-35$ & 1.92E-32 \\
\hline Immune response-regulating signaling pathway & 218/20447 & $49 / 458$ & $6.76 \mathrm{E}-35$ & $1.01 \mathrm{E}-31$ \\
\hline
\end{tabular}

Table 4 The top 20 pathways assigned to AIDS-related IncRNA HCP5 by our LncRNA2Function

\begin{tabular}{|c|c|c|c|c|c|}
\hline $\begin{array}{l}\text { Pahtway } \\
\text { database }\end{array}$ & Pahtway name & $\begin{array}{l}\text { Background } \\
\text { frequency }\end{array}$ & $\begin{array}{l}\text { Sample } \\
\text { frequency }\end{array}$ & P-value & Corrected P-value \\
\hline Reactome & Immune System & $1177 / 20447$ & $98 / 458$ & $1.66 \mathrm{E}-30$ & $2.14 \mathrm{E}-27$ \\
\hline KEGG & Natural killer cell mediated cytotoxicity & $219 / 20447$ & $38 / 458$ & $6.00 \mathrm{E}-23$ & 3.87E-20 \\
\hline PID & $\begin{array}{l}\text { Immunoregulatory interactions between a Lymphoid and a } \\
\text { non-Lymphoid cell }\end{array}$ & $104 / 20447$ & $28 / 458$ & $1.06 \mathrm{E}-22$ & 4.54E-20 \\
\hline Reactome & $\begin{array}{l}\text { Immunoregulatory interactions between a Lymphoid and a } \\
\text { non-Lymphoid cell }\end{array}$ & 202/20447 & $35 / 458$ & 3.36E-21 & $1.08 \mathrm{E}-18$ \\
\hline Reactome & Adaptive Immune System & $772 / 20447$ & $66 / 458$ & $4.68 \mathrm{E}-21$ & 1.21E-18 \\
\hline NetPath & TCR & $252 / 20447$ & $36 / 458$ & $6.84 \mathrm{E}-19$ & 1.47E-16 \\
\hline KEGG & Chemokine signaling pathway & 195/20447 & $30 / 458$ & $7.56 \mathrm{E}-17$ & 1.39E-14 \\
\hline PID & Generation of second messenger molecules & $15 / 20447$ & $11 / 458$ & 7.96E-16 & $1.28 \mathrm{E}-13$ \\
\hline KEGG & Osteoclast differentiation & $174 / 20447$ & $27 / 458$ & $2.20 \mathrm{E}-15$ & $3.16 \mathrm{E}-13$ \\
\hline PID & TCR signaling in naive CD4+ T cells & $80 / 20447$ & $19 / 458$ & $1.03 \mathrm{E}-14$ & $1.32 \mathrm{E}-12$ \\
\hline PID & TCR signaling in naive CD8+ T cells & $63 / 20447$ & $17 / 458$ & $2.63 \mathrm{E}-14$ & $3.09 \mathrm{E}-12$ \\
\hline PID & IL12-mediated signaling events & $81 / 20447$ & $18 / 458$ & $1.80 \mathrm{E}-13$ & $1.94 \mathrm{E}-11$ \\
\hline KEGG & Cytokine-cytokine receptor interaction & 291/20447 & $31 / 458$ & 6.97E-13 & $6.42 \mathrm{E}-11$ \\
\hline Reactome & Innate Immune System & $542 / 20447$ & $43 / 458$ & $6.96 \mathrm{E}-13$ & $6.42 \mathrm{E}-11$ \\
\hline KEGG & Hematopoietic cell lineage & 114/20447 & $20 / 458$ & $9.26 \mathrm{E}-13$ & 7.97E-11 \\
\hline KEGG & T cell receptor signaling pathway & $116 / 20447$ & $20 / 458$ & 1.30E-12 & $1.05 \mathrm{E}-10$ \\
\hline Reactome & Cell surface interactions at the vascular wall & $104 / 20447$ & $19 / 458$ & $1.62 \mathrm{E}-12$ & 1.23E-10 \\
\hline PID & Cell surface interactions at the vascular wall & $42 / 20447$ & $13 / 458$ & 4.26E-12 & $3.06 \mathrm{E}-10$ \\
\hline Reactome & Class A/1 (Rhodopsin-like receptors) & $319 / 20447$ & $31 / 458$ & 7.85E-12 & $5.33 \mathrm{E}-10$ \\
\hline PID & Fc-epsilon receptor I signaling in mast cells & $64 / 20447$ & $15 / 458$ & 8.34E-12 & $5.38 \mathrm{E}-10$ \\
\hline
\end{tabular}




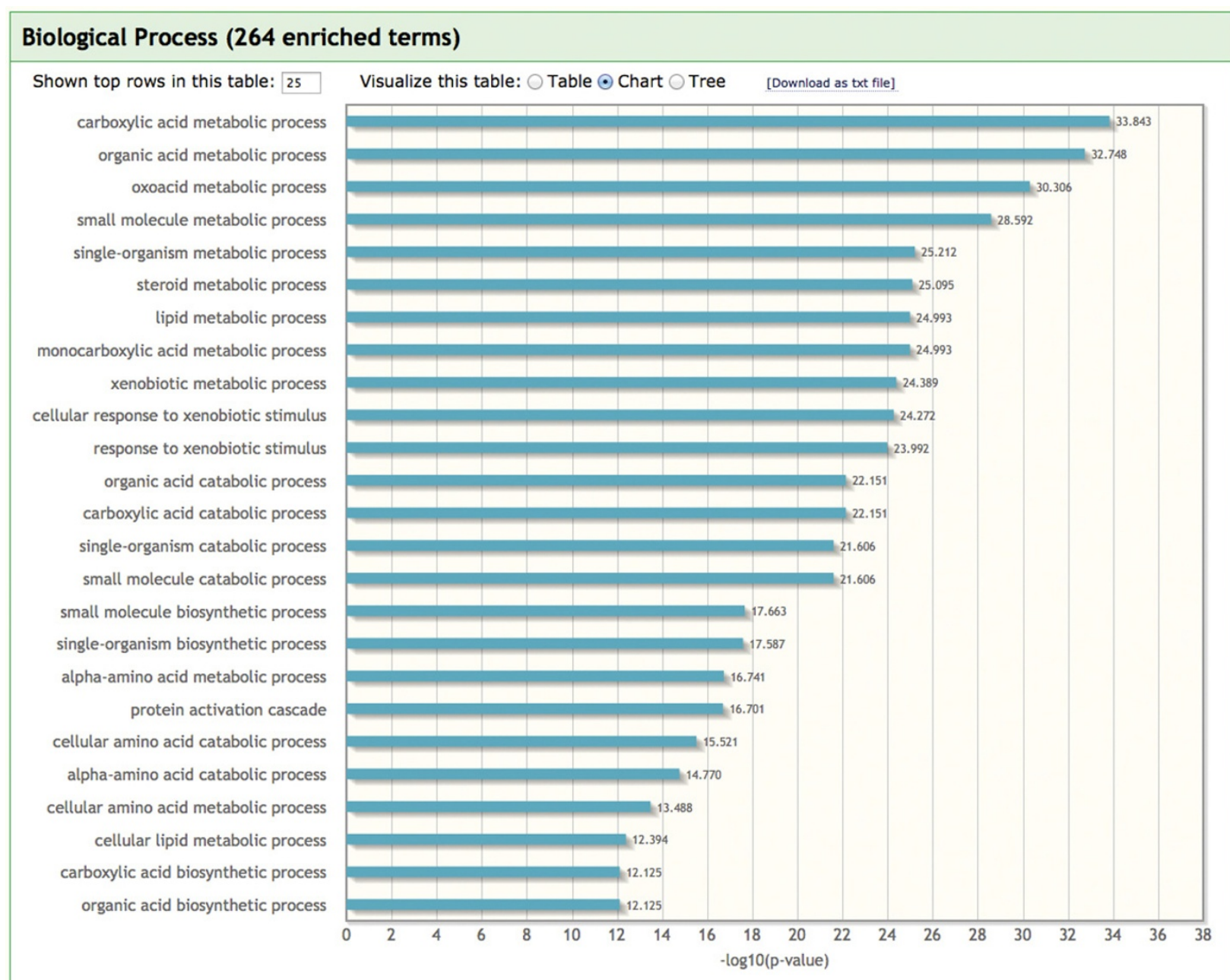

6394 GO Biological Process terms were tested using an annotated protein-coding gene count range [5, inf].

Figure 2 The top 25 statistically significant enriched GO biological processes assigned to liver-related HULC are associated with the metabolic function of liver.

$\mathrm{P}<0.0001$ ), and Lottin et al. showed that over-expression of H19 transcript is associated with cells exhibiting higher tumorigenic phenotypes and promotes tumor progression.

We applied the LncRNA2Function to the lncRNA $\mathrm{H} 19$ and found that it was annotated with 6 GO biological processes and 31 biological pathways. The GO terms includes female pregnancy (GO: 0007565), estrogen biosynthetic process (GO:0006703), growth hormone receptor signaling pathway (GO:0060396), cellular response to growth hormone stimulus (GO:0071378) and JAKSTAT cascade involved in growth hormone signaling pathway (GO:0060397), which suggest that H19 may play roles in infertility or breast cancer by participating in these biological processes. In addition, the cancerrelated lncRNA H19 was correctly annotated with many important caner pathways, such as PI3K-Akt signaling pathway, GPCR signaling-G alpha s Epac and ERK pathway, Nuclear signaling by ERBB4 pathway, Akt signaling pathway and JAK-STAT-Core cancer pathway. These results suggest that our LncRNA2Function correctly recall the known functions of $\mathrm{H} 19$.

\section{Case study 5: PCA3}

The lncRNA prostate cancer antigen 3 (PCA3) is a highly specific biomarker upregulated and plays crucial roles in prostate cancer $(\mathrm{PCa})$ [42-45]. Clarke et al. found that up-regulation of two new PCA3 isoforms in PCa tissues improves discrimination between $\mathrm{PCa}$ and benign prostatic hyperplasia (BPH). In 2012, the US Food and Drug Administration approved the use of the lncRNA PCA3 for the detection of prostate cancer.

To test whether our LncRNA2Function can annotate the PCA3 with prostate-related functions, we applied 
Table 5 Top 20 pathways enriched in protein-coding genes that are co-expressed with the liver-related IncRNA HULC

\begin{tabular}{|c|c|c|c|c|c|}
\hline $\begin{array}{l}\text { Pahtway } \\
\text { database }\end{array}$ & Pahtway name & Background frequency & Sample frequency & P-value & Corrected P-value \\
\hline Reactome & Metabolism & $1394 / 20447$ & $128 / 390$ & 6.17E-54 & $6.23 \mathrm{E}-51$ \\
\hline KEGG & Metabolic pathways & $1256 / 20447$ & 109/390 & 7.95E-43 & 4.01E-40 \\
\hline KEGG & Retinol metabolism & $69 / 20447$ & $29 / 390$ & $5.66 \mathrm{E}-32$ & $1.91 \mathrm{E}-29$ \\
\hline KEGG & Complement and coagulation cascades & $87 / 20447$ & $30 / 390$ & $6.18 \mathrm{E}-30$ & 1.56E-27 \\
\hline EHMN & Androgen and estrogen biosynthesis and metabolism & $90 / 20447$ & $30 / 390$ & $2.02 \mathrm{E}-29$ & 4.07E-27 \\
\hline Reactome & Biological oxidations & $151 / 20447$ & $36 / 390$ & $2.71 \mathrm{E}-29$ & 4.55E-27 \\
\hline KEGG & Drug metabolism - cytochrome P450 & $76 / 20447$ & $28 / 390$ & $5.84 \mathrm{E}-29$ & $8.41 \mathrm{E}-27$ \\
\hline KEGG & Metabolism of xenobiotics by cytochrome P450 & $87 / 20447$ & $29 / 390$ & $1.78 \mathrm{E}-28$ & $2.24 \mathrm{E}-26$ \\
\hline KEGG & Chemical carcinogenesis & $86 / 20447$ & $28 / 390$ & 3.33E-27 & $3.74 \mathrm{E}-25$ \\
\hline EHMN & Tyrosine metabolism & $113 / 20447$ & $30 / 390$ & 4.29E-26 & 4.33E-24 \\
\hline EHMN & Xenobiotics metabolism & $54 / 20447$ & $23 / 390$ & 9.33E-26 & 8.56E-24 \\
\hline Reactome & Metabolism of amino acids and derivatives & $159 / 20447$ & $32 / 390$ & 1.09E-23 & $9.20 \mathrm{E}-22$ \\
\hline Wikipathways & metapathway biotransformation & $190 / 20447$ & $34 / 390$ & 2.43E-23 & $1.88 \mathrm{E}-21$ \\
\hline EHMN & Linoleate metabolism & $75 / 20447$ & $24 / 390$ & 2.81E-23 & 2.03E-21 \\
\hline Wikipathways & cytochrome P450 & $68 / 20447$ & $23 / 390$ & $5.40 \mathrm{E}-23$ & $3.63 \mathrm{E}-21$ \\
\hline Wikipathways & Complement and Coagulation Cascades & $60 / 20447$ & $22 / 390$ & 5.97E-23 & 3.77E-21 \\
\hline EHMN & Leukotriene metabolism & $102 / 20447$ & $26 / 390$ & 2.87E-22 & $1.70 \mathrm{E}-20$ \\
\hline Reactome & Phase 1 - Functionalization of compounds & $74 / 20447$ & $23 / 390$ & $5.01 \mathrm{E}-22$ & $2.81 \mathrm{E}-20$ \\
\hline KEGG & Drug metabolism - other enzymes & $53 / 20447$ & $20 / 390$ & 2.85E-21 & $1.51 \mathrm{E}-19$ \\
\hline Reactome & Xenobiotics & $15 / 20447$ & $13 / 390$ & $3.68 \mathrm{E}-21$ & 1.86E-19 \\
\hline
\end{tabular}

the LncRNA2Function to the PCA3. LncRNA2Function first identified 77 protein-coding genes that are coexpressed with the PCA3 and then annotated it with only one pathway named 'Regulation of Androgen receptor activity' (corrected P-value: 0.020385 ). This pathway has 62 genes, which includes 4 protein-coding genes that are co-expressed with the PCA3. These four genes are HOXB13, KLK3, KLK2 and SPDEF that have been validated to be useful in the diagnosis and monitoring of prostatic carcinoma and be suitable target for developing specific cancer therapies. Consequently, IncRNA2Function can correctly predict the functions of PCA3 by its co-expressed protein-coding genes.

\section{Functional annotation for a set of human IncRNAs}

High-throughput genomic technologies like lncRNA microarray and RNA-Seq usually generate hundreds of candidate lncRNA genes of interest, such as a cluster of co-expressed lncRNA genes across multiple conditions or a set of differentially expressed lncRNAs between cancer and normal samples. To manually map each lncRNA to functional terms is by far a simple task. Therefore, how to identify significantly enriched functions among the set of lncRNAs is an important downstream task for interpreting high-throughput experimental data.

As a proof-of-concept, a set of liver-specific lncRNAs and a set of heart-specific lncRNAs inferred from RNASeq data of 19 human normal tissues were used as examples to show the functionality of our lncRNA2Function system in annotating a set of lncRNAs of interest, respectively. As expected, lncRNA2Function correctly assigned the functional terms to the two distinct sets of lncRNAs. Users can test these two sets or their own lncRNA sets at our 'LncRNA set analyzer' web interface http://mlg.hit. edu.cn/lncrna2function/lncrna_enrich.jsp.

\section{Web interface of LncRNA2Function}

To facilitate researchers to access the functional annotations of lncRNA genes, we developed a web interface named 'LncRNA annotation browser', which is a userfriendly interface to browse or search lncRNAs associated with a specific functional term, or functional terms associated with a given lncRNA. To enable researchers to analyze a set of lncRNA genes of their interest, we implemented a web interface titled 'LncRNA set analyzer', which can help investigators to annotate a set of lncRNAs with Gene Ontology and 4,380 biological pathways curated from 12 pathway databases. In addition, we developed a web interface titled 'LncRNA expression viewer' to facilitate investigators to graphically view the expression dynamics of genes across multiple human normal tissues. Users can not only view expression value of a single lncRNA or protein-coding gene across 19 human normal tissues, but also simultaneously view the expression index of both lncRNA and protein-coding genes to learn about whether they are co-expressed across the 19 tissues. Furthermore, we provide a submission page that allows other researchers to submit known 


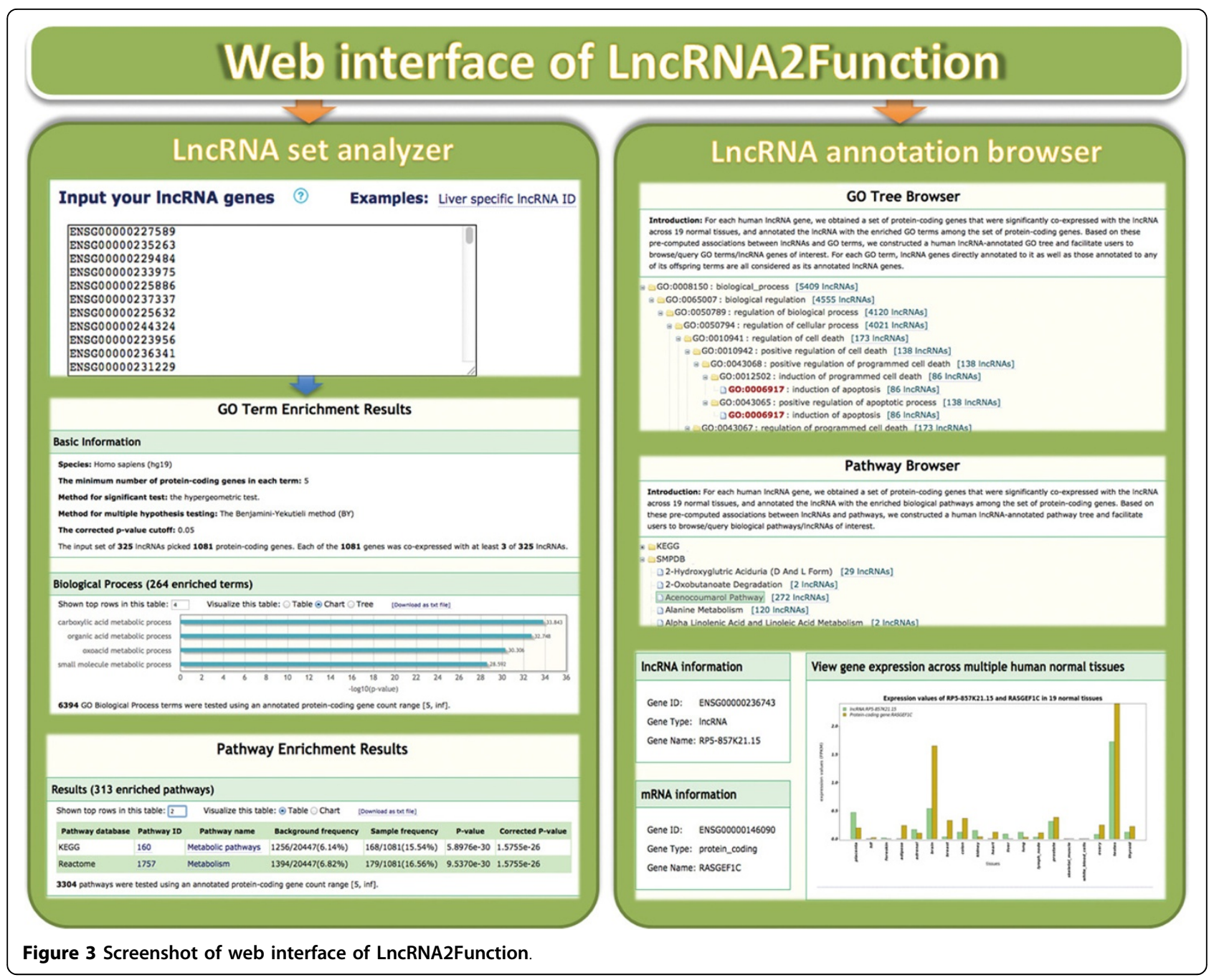

functional annotations of lncRNAs that are not documented in our LncRNA2Function system (Figure 3). They do not have to be an author on the original study to submit a record. Once approved by the submission review committee, the submitted records will be made available to the public in the coming release. LncRNA2Function is freely accessible at http://mlg.hit.edu.cn/ lncrna2function.

\section{Conclusions}

Thousands of human lncRNAs have been identified in recent several years, while the vast majority of the lncRNAs remain to be functionally characterized. In this study, we functionally annotate 9,625 human lncRNAs with the enriched functions among the protein-coding genes that are co-expressed with each lncRNA. Furthermore, we developed a web interface, which facilitates researchers to search the functions of a specific lncRNA or the lncRNAs associated with a given functional term, or annotate functionally a set of human lncRNAs of interest. The lncRNA2Function will become an important tool for investigating functions of human lncRNAs.

\section{Competing interests}

The authors declare that they have no competing interests

\section{Authors' contributions}

YW and YL conceived and designed the experiments. QJ, RM, XW, SJ, TZ, RT and JP performed the experiments and analyzed the data. QJ and JW designed and developed the web interface. QJ, YW and YL wrote the paper.

\section{Acknowledgements}

The Natural Science Foundation of China (NSFC) [61102149, 61173085], Fundamental Research Funds for the Central Universities [HIT NSRIF. 2010057, HIT BRETIII.201219] and the China National 863 High-Tech Program (2012AA02A602, 2012AA020404 and 2012AA02A601). Funding for open access publication: NSFC [61102149]

This article has been published as part of BMC Genomics Volume 16 Supplement 3, 2015: Selected articles from the 10th International Symposium on Bioinformatics Research and Applications (ISBRA-14): Genomics. The full contents of the supplement are available online at http:// www.biomedcentral.com/bmcgenomics/supplements/16/S3. 


\section{Authors' details}

'School of Life Science and Technology, Harbin Institute of Technology, Harbin, Heilongjiang 150001, China. ${ }^{2}$ School of Computer Science and Technology, Harbin Institute of Technology, Harbin, Heilongjiang 150001, China. ${ }^{3}$ School of Software, Harbin Institute of Technology, Harbin, Heilongjiang 150001, China. ${ }^{4}$ Department of Mathematics, Harbin Institute of Technology, Harbin, Heilongjiang, 150001, China.

Published: 29 January 2015

\section{References}

1. Guttman M, Donaghey J, Carey BW, Garber M, Grenier JK, Munson G, Young $G$, Lucas $A B, A c h R$, Bruhn $L$, et al: lincRNAs act in the circuitry controlling pluripotency and differentiation. Nature 2011, 477(7364):295-300

2. Dimitrova N, Zamudio JR, Jong RM, Soukup D, Resnick R, Sarma K, Ward AJ, Raj A, Lee JT, Sharp PA, et al: LincRNA-p21 activates p21 in cis to promote Polycomb target gene expression and to enforce the G1/S checkpoint. Molecular cell 2014, 54(5):777-790.

3. Chen G, Wang Z, Wang D, Qiu C, Liu M, Chen X, Zhang Q, Yan G, Cui Q: LncRNADisease: a database for long-non-coding RNA-associated diseases. Nucleic acids research 2013, 41(D1):D983-986.

4. Barnhill LM, Williams RT, Cohen O, Kim Y, Batova A, Mielke JA, Messer K, Pu M, Bao L, Yu AL, et al: High Expression of CAl2, a 9p21-Embedded Long Noncoding RNA, Contributes to Advanced-Stage Neuroblastoma. Cancer research 2014, 74(14):3753-3763.

5. Carpenter S, Aiello D, Atianand MK, Ricci EP, Gandhi P, Hall LL, Byron M, Monks B, Henry-Bezy M, Lawrence JB, et al: A long noncoding RNA mediates both activation and repression of immune response genes. Science 2013, 341(6147):789-792.

6. Sun L, Goff LA, Trapnell C, Alexander R, Lo KA, Hacisuleyman E, Sauvageau M, Tazon-Vega B, Kelley DR, Hendrickson DG, et al: Long noncoding RNAs regulate adipogenesis. Proceedings of the National Academy of Sciences of the United States of America 2013, 110(9):3387-3392.

7. Mercer TR, Dinger ME, Mattick JS: Long non-coding RNAs: insights into functions. Nature reviews Genetics 2009, 10(3):155-159.

8. Chu C, Qu K, Zhong FL, Artandi SE, Chang HY: Genomic maps of long noncoding RNA occupancy reveal principles of RNA-chromatin interactions. Molecular cell 2011, 44(4):667-678.

9. Simon MD, Wang $\mathrm{Cl}$, Kharchenko PV, West JA, Chapman BA, Alekseyenko AA, Borowsky ML, Kuroda MI, Kingston RE: The genomic binding sites of a noncoding RNA. Proceedings of the National Academy of Sciences of the United States of America 2011, 108(51):20497-20502.

10. Lee HK, Hsu AK, Sajdak J, Qin J, Pavlidis P: Coexpression analysis of human genes across many microarray data sets. Genome research 2004, 14(6):1085-1094

11. Eisen MB, Spellman PT, Brown PO, Botstein D: Cluster analysis and display of genome-wide expression patterns. Proceedings of the National Academy of Sciences of the United States of America 1998, 95(25):14863-14868.

12. Guttman M, Amit I, Garber M, French C, Lin MF, Feldser D, Huarte M, Zuk O, Carey BW, Cassady JP, et al: Chromatin signature reveals over a thousand highly conserved large non-coding RNAs in mammals. Nature 2009, 458(7235):223-227.

13. Guo X, Gao L, Liao Q, Xiao H, Ma X, Yang X, Luo H, Zhao G, Bu D, Jiao F, et al: Long non-coding RNAs function annotation: a global prediction method based on bi-colored networks. Nucleic acids research 2013, 41(2):e35.

14. Liao Q, Liu C, Yuan X, Kang S, Miao R, Xiao H, Zhao G, Luo H, Bu D, Zhao H, et al: Large-scale prediction of long non-coding RNA functions in a coding-non-coding gene co-expression network. Nucleic acids research 2011, 39(9):3864-3878

15. Harrow J, Frankish A, Gonzalez JM, Tapanari E, Diekhans M, Kokocinski F, Aken BL, Barrell D, Zadissa A, Searle S, et al: GENCODE: the reference human genome annotation for The ENCODE Project. Genome research 2012, 22(9):1760-1774.

16. Ashburner M, Ball CA, Blake JA, Botstein D, Butler H, Cherry JM, Davis AP, Dolinski K, Dwight SS, Eppig JT, et al: Gene ontology: tool for the unification of biology. The Gene Ontology Consortium. Nature genetics 2000, 25(1):25-29.

17. Kamburov A, Stelzl U, Lehrach H, Herwig R: The ConsensusPathDB interaction database: 2013 update. Nucleic acids research 2013, 41 Database: D793-800.
18. Kim D, Pertea G, Trapnell C, Pimentel H, Kelley R, Salzberg SL: TopHat2: accurate alignment of transcriptomes in the presence of insertions, deletions and gene fusions. Genome biology 2013, 14(4):R36.

19. Trapnell C, Williams BA, Pertea G, Mortazavi A, Kwan G, van Baren MJ, Salzberg SL, Wold BJ, Pachter L: Transcript assembly and quantification by RNA-Seq reveals unannotated transcripts and isoform switching during cell differentiation. Nature biotechnology 2010, 28(5):511-515.

20. Benjamini YaY D: the control of false discovery rate in multiple testing under dependency. Ann Stat 2001, 29:1165-1168.

21. Benjamini Y, Hochberg Y: Controlling the false discovery rate: a practical and powerful approach to multiple testing. Journal of the Royal Statistical Society Series B 1995, 57: 289-300.

22. Shaffer JP: Controlling the false discovery rate with constraints: the Newman-Keuls test revisited. Biom J 2007, 49:136-143.

23. Qureshi IA, Mehler MF: Emerging roles of non-coding RNAs in brain evolution, development, plasticity and disease. Nature reviews Neuroscience 2012, 13(8):528-541.

24. Hu W, Yuan B, Flygare J, Lodish HF: Long noncoding RNA-mediated antiapoptotic activity in murine erythroid terminal differentiation. Genes \& development 2011, 25(24):2573-2578.

25. Yoon JH, Abdelmohsen K, Srikantan S, Yang X, Martindale JL, De S, Huarte M, Zhan M, Becker KG, Gorospe M: LincRNA-p21 suppresses target mRNA translation. Molecular cell 2012, 47(4):648-655.

26. Gupta RA, Shah N, Wang KC, Kim J, Horlings HM, Wong DJ, Tsai MC, Hung T, Argani P, Rinn JL, et al: Long non-coding RNA HOTAIR reprograms chromatin state to promote cancer metastasis. Nature 2010, 464(7291):1071-1076.

27. Rinn JL, Kertesz M, Wang JK, Squazzo SL, Xu X, Brugmann SA, Goodnough LH, Helms JA, Farnham PJ, Segal E, et al: Functional demarcation of active and silent chromatin domains in human HOX loci by noncoding RNAs. Cell 2007, 129(7):1311-1323.

28. Niinuma T, Suzuki H, Nojima M, Nosho K, Yamamoto H, Takamaru H, Yamamoto E, Maruyama R, Nobuoka T, Miyazaki Y, et al: Upregulation of miR-196a and HOTAIR drive malignant character in gastrointestinal stromal tumors. Cancer research 2012, 72(5):1126-1136.

29. Rodriguez-Novoa S, Cuenca L, Morello J, Cordoba M, Blanco F, JimenezNacher I, Soriano V: Use of the HCP5 single nucleotide polymorphism to predict hypersensitivity reactions to abacavir: correlation with HLAB*5701. The Journal of antimicrobial chemotherapy 2010, 65(8):1567-1569.

30. Colombo S, Rauch A, Rotger M, Fellay J, Martinez R, Fux C, Thurnheer C, Gunthard HF, Goldstein DB, Furrer H, et al: The HCP5 single-nucleotide polymorphism: a simple screening tool for prediction of hypersensitivity reaction to abacavir. The Journal of infectious diseases 2008, 198(6):864-867.

31. Yoon W, Ma BJ, Fellay J, Huang W, Xia SM, Zhang R, Shianna KV, Liao HX, Haynes BF, Goldstein DB: A polymorphism in the HCP5 gene associated with HLA-B*5701 does not restrict HIV-1 in vitro. AIDS 2010, 24(1):155-157.

32. Wang J, Liu X, Wu H, Ni P, Gu Z, Qiao Y, Chen N, Sun F, Fan Q: CREB up-regulates long non-coding RNA, HULC expression through interaction with microRNA-372 in liver cancer. Nucleic acids research 2010, 38(16):5366-5383.

33. Panzitt K, Tschernatsch MM, Guelly C, Moustafa T, Stradner M, Strohmaier HM, Buck CR, Denk H, Schroeder R, Trauner M, et al: Characterization of HULC, a novel gene with striking up-regulation in hepatocellular carcinoma, as noncoding RNA. Gastroenterology 2007, 132(1):330-342.

34. Matouk IJ, Abbasi I, Hochberg A, Galun E, Dweik H, Akkawi M: Highly upregulated in liver cancer noncoding RNA is overexpressed in hepatic colorectal metastasis. European journal of gastroenterology \& hepatology 2009, 21(6):688-692.

35. Korucuoglu U, Biri AA, Konac E, Alp E, Onen $I H$, Ihan $M N$, Turkyilmaz E, Erdem A, Erdem M, Menevse S: Expression of the imprinted IGF2 and H19 genes in the endometrium of cases with unexplained infertility. European journal of obstetrics, gynecology, and reproductive biology 2010, 149(1):77-81

36. Lottin S, Adriaenssens E, Dupressoir T, Berteaux N, Montpellier C, Coll J, Dugimont T, Curgy JJ: Overexpression of an ectopic $\mathrm{H} 19$ gene enhances the tumorigenic properties of breast cancer cells. Carcinogenesis 2002, 23(11):1885-1895.

37. Berteaux N, Aptel N, Cathala G, Genton C, Coll J, Daccache A, Spruyt N, Hondermarck H, Dugimont T, Curgy JJ, et al: A novel H19 antisense RNA 
overexpressed in breast cancer contributes to paternal IGF2 expression. Molecular and cellular biology 2008, 28(22):6731-6745.

38. Douc-Rasy S, Barrois M, Fogel S, Ahomadegbe JC, Stehelin D, Coll J, Riou G: High incidence of loss of heterozygosity and abnormal imprinting of H19 and IGF2 genes in invasive cervical carcinomas. Uncoupling of H19 and IGF2 expression and biallelic hypomethylation of H19. Oncogene 1996, 12(2):423-430.

39. Song JY, Lee JH, Joe CO, Lim DS, Chung JH: Retrotransposon-specific DNA hypomethylation and two-step loss-of-imprinting during WW45 haploinsufficiency-induced hepatocarcinogenesis. Biochemical and biophysical research communications 2011, 404(2):728-734

40. Matouk IJ, DeGroot N, Mezan S, Ayesh S, Abu-lail R, Hochberg A, Galun E: The $\mathrm{H} 19$ non-coding RNA is essential for human tumor growth. PloS one 2007, 2(9):e845.

41. Verhaegh GW, Verkleij L, Vermeulen SH, den Heijer M, Witjes JA, Kiemeney LA: Polymorphisms in the $\mathrm{H} 19$ gene and the risk of bladder cancer. European urology 2008, 54(5):1118-1126.

42. Clarke RA, Zhao Z, Guo AY, Roper K, Teng L, Fang ZM, Samaratunga H, Lavin MF, Gardiner RA: New genomic structure for prostate cancer specific gene PCA3 within BMCC1: implications for prostate cancer detection and progression. PloS one 2009, 4(3):e4995.

43. Klecka J, Holubec L, Pesta M, Topolcan O, Hora M, Eret V, Finek J, ChottovaDvorakova M, Babjuk M, Novak K, et al: Differential display code 3 (DD3/ PCA3) in prostate cancer diagnosis. Anticancer research 2010, 30(2):665-670.

44. Tinzl M, Marberger M, Horvath S, Chypre C: DD3PCA3 RNA analysis in urine-a new perspective for detecting prostate cancer. European urology 2004, 46(2):182-186, discussion 187.

45. Haese A, de la Taille A, van Poppel H, Marberger M, Stenzl A, Mulders PF, Huland H, Abbou CC, Remzi M, Tinzl M, et al: Clinical utility of the PCA3 urine assay in European men scheduled for repeat biopsy. European urology 2008, 54(5):1081-1088.

doi:10.1186/1471-2164-16-S3-S2

Cite this article as: Jiang et al.: LncRNA2Function: a comprehensive resource for functional investigation of human IncRNAs based on RNAseq data. BMC Genomics 2015 16(Suppl 3):S2.

\section{Submit your next manuscript to BioMed Central and take full advantage of:}

- Convenient online submission

- Thorough peer review

- No space constraints or color figure charges

- Immediate publication on acceptance

- Inclusion in PubMed, CAS, Scopus and Google Scholar

- Research which is freely available for redistribution

Submit your manuscript at www.biomedcentral.com/submit 